\title{
COTS Acquisition Evaluation Process: Preacher's Practice
}

Vijay Sai

January 2004

COTS-Based Systems Initiative

Unlimited distribution subject to the copyright.

Technical Note

CMU/SEI-2004-TN-001 
The Software Engineering Institute is a federally funded research and development center sponsored by the U.S. Department of Defense.

Copyright 2004 by Carnegie Mellon University.

NO WARRANTY

THIS CARNEGIE MELLON UNIVERSITY AND SOFTWARE ENGINEERING INSTITUTE MATERIAL IS FURNISHED ON AN "AS-IS" BASIS. CARNEGIE MELLON UNIVERSITY MAKES NO WARRANTIES OF ANY KIND, EITHER EXPRESSED OR IMPLIED, AS TO ANY MATTER INCLUDING, BUT NOT LIMITED TO, WARRANTY OF FITNESS FOR PURPOSE OR MERCHANTABILITY, EXCLUSIVITY, OR RESULTS OBTAINED FROM USE OF THE MATERIAL. CARNEGIE MELLON UNIVERSITY DOES NOT MAKE ANY WARRANTY OF ANY KIND WITH RESPECT TO FREEDOM FROM PATENT, TRADEMARK, OR COPYRIGHT INFRINGEMENT.

Use of any trademarks in this report is not intended in any way to infringe on the rights of the trademark holder.

Internal use. Permission to reproduce this document and to prepare derivative works from this document for internal use is granted, provided the copyright and "No Warranty" statements are included with all reproductions and derivative works.

External use. Requests for permission to reproduce this document or prepare derivative works of this document for external and commercial use should be addressed to the SEI Licensing Agent.

This work was created in the performance of Federal Government Contract Number F19628-00-C-0003 with Carnegie Mellon University for the operation of the Software Engineering Institute, a federally funded research and development center. The Government of the United States has a royalty-free government-purpose license to use, duplicate, or disclose the work, in whole or in part and in any manner, and to have or permit others to do so, for government purposes pursuant to the copyright license under the clause at 252.227-7013.

For information about purchasing paper copies of SEI reports, please visit the publications portion of our Web site (http://www.sei.cmu.edu/publications/pubweb.html). 


\section{Contents}

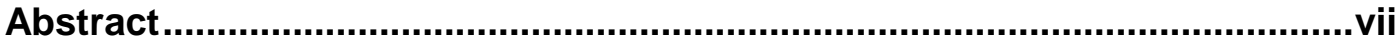

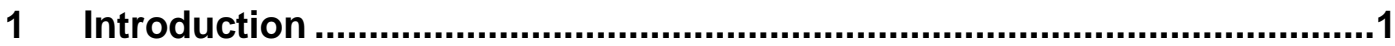

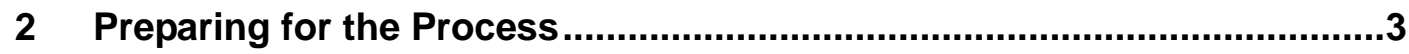

2.1 Problem Statement Definition ......................................................

2.2 Defining Stakeholders................................................................. 4

2.3 Definition of Requirements and Preferences.................................. 5

2.4 Definition of Expectations from the New System .............................

2.5 Definition of Expectations About Vendor ........................................ 7

2.6 Definition of the Grading Scale .................................................. 8

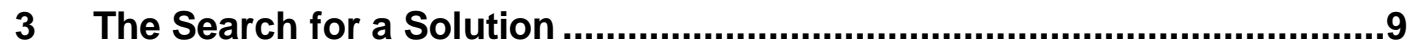

3.1 Representation at Key IT Conferences ...............................................

3.2 Shortlisting Probable Vendors (COTS and Custom

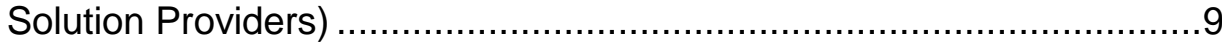

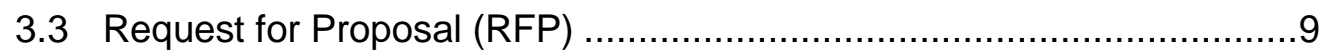

3.4 On-Site Pre-Bid Conference .................................................. 10

3.5 Proposal Receipt and Opening ............................................ 10

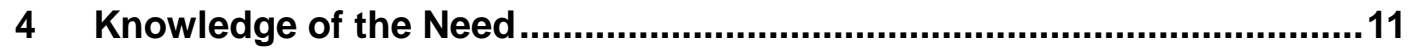

5 Proposal Evaluation .........................................................................14

5.1 Proposal Evaluation Criteria .....................................................14

5.2 Functional Specifications Document ......................................... 15

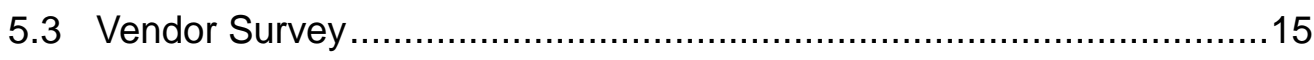

5.4 Process Definition ................................................................. 15

5.5 Consolidation of Comments and Grades ........................................16

5.6 Reference Calls, Vendor Calls, and Research

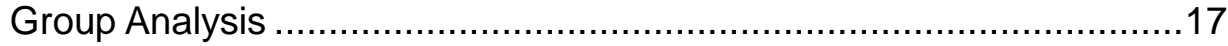

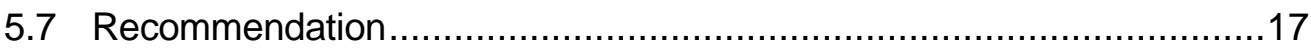

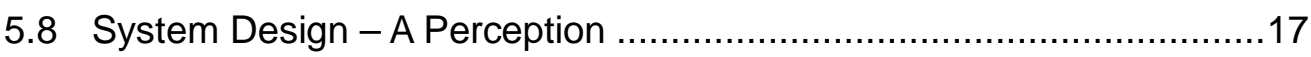




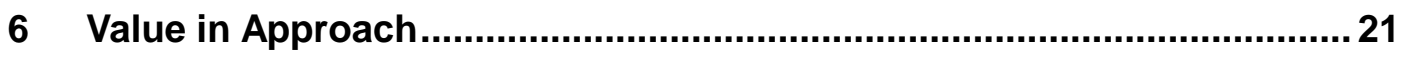

6.1 Lesson 1 - Faith Is Fifty Percent of Healing …................................. 21

6.2 Lesson 2 - Knowledge Is Power ................................................ 21

6.3 Lesson 3 - We Reap What We Sow ............................................ 22

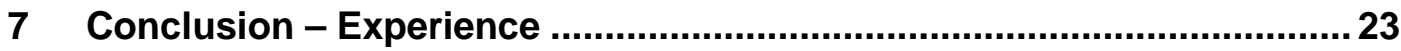

7.1 Comments from the Team Members on Their Experience ..................23

7.2 Expectations ...................................................................... 24

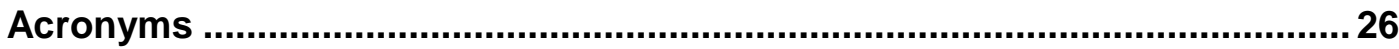

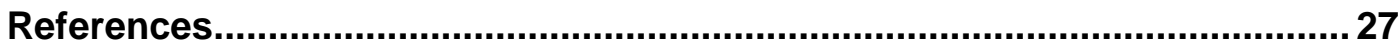




\section{List of Figures}

Figure 1: Diagrammatic Representation of the Product Selection Process ............3

Figure 2: Context Diagram Representing the Integrated Environment ................19 


\section{List of Tables}

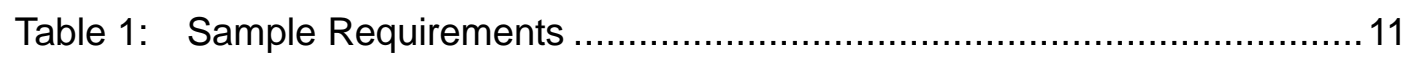

Table 2: Illustration of the Evaluation Template-A Sample ..............................15

Table 3: Illustration of the Grading Scale Used-A Sample ...............................16 


\section{Abstract}

This paper reflects a successful effort to apply commercial off-the-shelf (COTS)-based engineering principles to a software acquisition by the Financial and Business Services (FABS) and Information Technology (IT) departments at the Software Engineering Institute. The team responsible for the execution of the project was guided by the principles taught in the "COTS-Based Systems for Program Managers" and "COTS Software Evaluation for Practitioners" training programs conducted by the COTS-Based Systems Initiative at the Software Engineering Institute. Some of the major expectations set and realized included precise comprehension of requirements and preferences, ability to identify weak links in the proposed solutions, support for the "buy versus build" decision and the product recommendation, the promise of a shorter implementation phase, and brimming confidence based on a well-informed project approach. 


\section{Introduction}

In late 1999, Carnegie Mellon University (CMU) had implemented the Oracle Enterprise Resource Planning (ERP) System, a suite of business applications. The ERP system replaced the then existing transaction processing systems, with the promise of extending standardizationacross the global organization - of the way financial transactions would be recorded, managed, and maintained. The Software Engineering Institute (SEI) was among several constituents of CMU that were to be served with this system through a central Information Technology (IT) services deployment. The system afforded several extraordinary capabilities for automating bookkeeping and consolidation functions. But it had certain shortcomings: one was an inability to maintain budgets in a manner that would serve the business goals of the SEI. This was a major concern. The situation warranted the continued use of the faltering budget system that had been built internally several years prior (1993). The system was faltering because it needed to be modified substantially to accommodate several new needs created by the advent of the Oracle ERP system.

We found that the dream of an ERP system eliminating all the problems would elude us. We were trying to establish dependencies between two systems that had no capability built in to support such an effort. Thus arose the need to find a suitable solution to a serious problem. We saw two choices:

1. Change the business process to suit the ERP system.

2. Appropriately change the existing in-house system.

We did not consider the first option, since it had potential to affect a wide section of the CMU business community, and would have required elaborate business considerations specific to the various entities within CMU and increased time to deploy a solution in a project of such scale and complexity.

We chose the second option and ran into the wall, since reality does not allow the molding of one product to fit another's needs without adverse consequences. Challenges were posed; we would meet the challenge and attempt to move on. The monster would raise its head and exhibit a different behavior and be tamed again until all the troubles surfaced at once, taking us to a point of no return. We found the main ill effects of this phenomenon to be the tremendous effort directed at keeping the business process from failing. Declining productivity, user frustration, delayed decisions, quick workarounds, and questionable numbers were some effects that we experienced. At this juncture, we reached a decision to scour the marketplace in an effort to find a commercial off-the-shelf (COTS) solution. A team of five members-a combination of technical and business domain experts-were called upon by management to handle the task of steering the rocky boat to calmer seas. This paper attempts to shed light on the process with the hope that it 
can serve as a reference for the readers who expect to embark on projects involving COTS acquisitions. 


\section{Preparing for the Process}

Finding a COTS product proved problematic. This was partly because the peculiarities of our FFRDC (Federally Funded Research and Development Center)/Higher Education financial process were not entirely addressed by the marketplace. Therefore, the Chief Financial Officer was inspired to request that the COTS Program specialists provide guidance on the project, with intent to procure an off-the-shelf solution. We cannot but be thankful to him for that decision. Training in COTS software acquisition techniques soon followed. The techniques learned were applied in the product evaluation process. The COTS Program specialist(s) participated in each meeting. This greatly influenced the coining of the title to this paper's series. The application of these techniques is discussed at length in this paper. Each sub-section below maps to the process recommended in the COTS training, and was of course tailored to suit our situation.

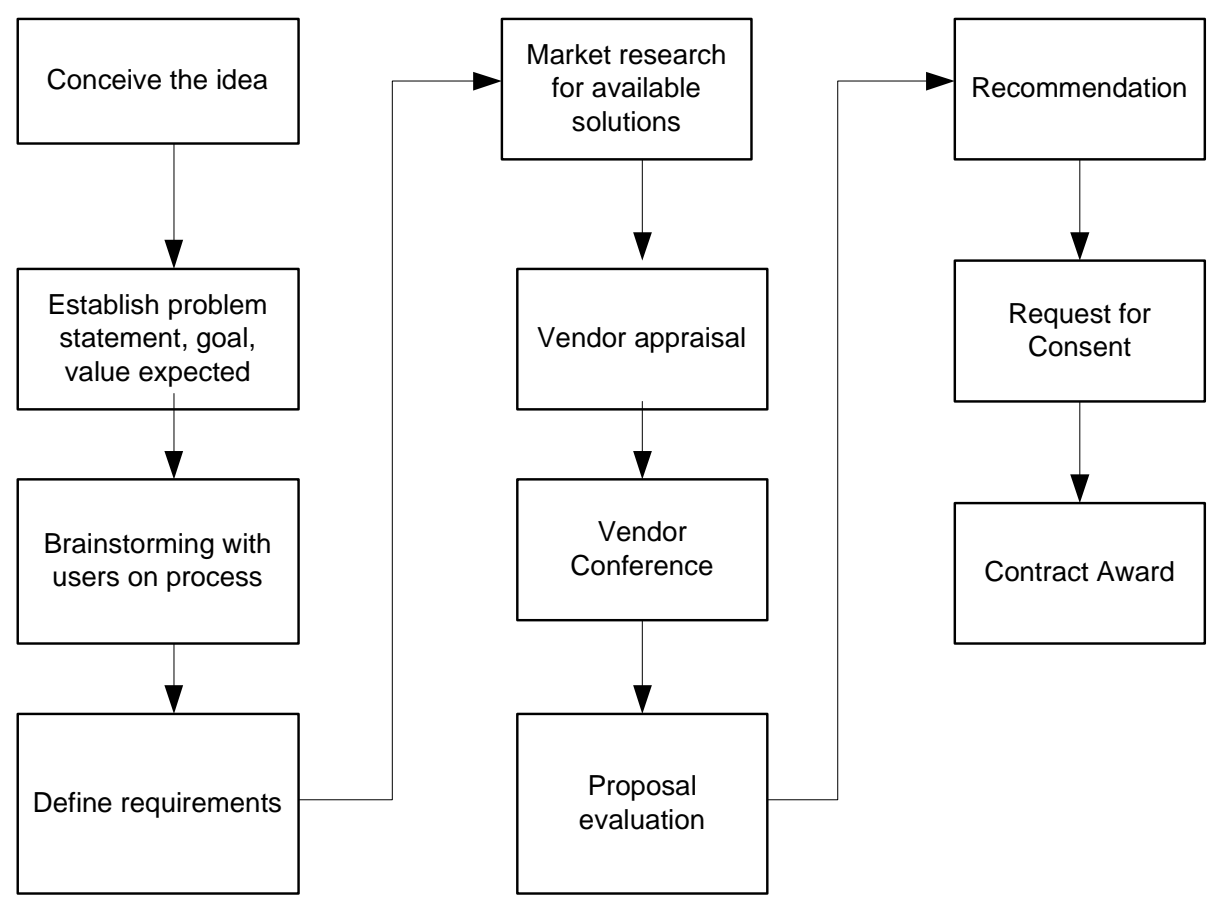

Figure 1: Diagrammatic Representation of the Product Selection Process

\subsection{Problem Statement Definition}

It was very important that we understand the problems with the existing system so we could determine the needs to be satisfied by the new system. This knowledge later helped us spot weaknesses in the proposals resulting from our quest. After evaluating all options available inhouse and on campus we concluded that much was left to be desired towards fulfilling the 
organization's needs. For example, we needed the capacity to budget by dollars and full time equivalent (FTE), budget people across projects and vice versa with an automatic consolidation capability, accommodate multiple accounting structures within one application, and reduce the maintenance overhead. In attempting to derive these capabilities, we were conscious of ensuring that problems (for example, the inability to integrate with other systems critical to the environment, inability to make modifications driven by change), which were agonizing attributes of the present system, would also need to be mitigated.

Given the above situation we reached a decision to go out to the marketplace to find a solution that would not only address the deficiencies that we were encountering with the available SEI/CMU systems, but would also provide some absolutely essential capabilities that would simplify the process of budgeting and reporting.

\subsection{Defining Stakeholders}

COTS product acquisition techniques suggest that the right mix of stakeholders should be involved on the project. It is important to identify the appropriate stakeholders, since they will bring considerable knowledge regarding the usefulness of various aspects of the product. To aid in identifying the right combination of stakeholders, we considered the following questions.

Who would derive value from the system?

In our case the business managers of various research initiatives and the financial groups that were supporting these business/program groups were to derive the maximum value by way of being able to record, maintain, manage, and report on the budgets and the related actual expenditure.

Who would sponsor the project?

The onus was on the Financial and Business Services Management Group to provide this key management function, so they would be driving the project.

Who would grant post-implementation support?

Representatives of the Information Technology organization that would house and administer the new system were brought on board, to contribute to the understanding of the new system's impact on the IT Enterprise Level Infrastructure.

Who owns the systems that the new system will depend on or may have to guarantee services to?

Functional and IT organizations representing the various systems that were to integrate with the new system were included. This would foster a collective understanding of the changes in the enterprise architecture that the new system would cause or require. 
Who would support the contractual and procurement aspects of the acquisition process?

We brought on board personnel from the Purchasing Offices on campus and within the SEI to ensure an understanding of the financial and legal obligations to which we would be committing ourselves. Their oversight would also help avoid licensing restrictions that might hinder appropriate use or bear negative cost impact.

Representatives from these areas with necessary functional and technical expertise were determined to be the stakeholders. Defining the group in this manner would ensure that we could draw upon their expertise to guide the project to its desired destiny. Their participation - to the ideal degree-was necessitated by the fact that multiple systems would be involved in the final integration.

The team members who had the task of selecting stakeholders understood the organizational structure to which the various stakeholders belonged. This enabled them to identify the desired players based on their usefulness in rendering value and success to the project.

We were very fortunate in having stakeholders who were very cooperative during the entire process and were always willing to contribute their best, through the sharing of their valuable knowledge and expertise, which we believe was very critical to the success of the evaluation process.

\subsection{Definition of Requirements and Preferences}

COTS solutions must be evaluated for their ability to satisfy the requirements that initiated their quest. Acquiring thorough knowledge of requirements is highly essential as well as time consuming. Typically, adequate time is not spent in this regard. It is one of the areas one must revisit at the first signs of major usability inefficiencies in the deployed system. There are two approaches to this phase within COTS based implementations:

- Build or change functional/technical environment around that of the COTS product chosen.

- Find the COTS product that is most suitable to the functional/technical environment prevalent.

The chance of finding a product that satisfies all requirements is remote. At best a COTS product might satisfy several requirements, but rarely all. In such cases tradeoffs may be essential or changes to the functional/technical environment may be necessary. Requirements that still need to be satisfied are addressed through additional COTS components or by custom development. In either case it is important that we know the requirements. Before we proceed any further, let us understand the term "requirement." 
A requirement is a functional or technical need that must be satisfied by the chartered system within the given operating environment. Failure to satisfy any of the requirements bears a highly adverse and unjustifiable functional or technical disability in fulfilling the main objectives of the implementing organization. Obviously the people who should be involved in the definition of requirements are those who use it and maintain it; their help makes it easier to identify the broad business and technical needs that must be satisfied by the system. In our project, we assigned people to gather these needs and document the specifics under each category. Within a couple of brainstorming sessions, a list of 11 requirements came to light and a partial list is reproduced in Table 1 in Section 4. This process brought about an understanding of the current environment in light of these requirements, the needs for the future, and the evolutionary change that must be factored within the scope of each of these requirements.

The approach we took was as follows:

1. Identify the external systems involved namely, Oracle ERP system and Human Resource Information (HRIS) system.

2. Identify the system environment in both the above cases.

3. Identify the system environment into which the new system would be introduced.

4. Identify the business processes that are mandatory.

5. Identify the areas causing functional frustration.

6. Identify the persons that have a good understanding of the various aspects and pair them up to deliver the requirements specifications.

7. Identify the direction of the organization in relation to the marketplace and the technology.

8. Brainstorm to segregate the list into requirements and preferences.

9. Draw up a functional specifications document.

It is not an uncommon industry practice to select the vendor and then have the requirements drafted. However, this approach bears the potential of opening the doors for modification of a vendor's system to fit the requirements. In the event this were not feasible, processes would need to be changed or complex customizations would have to be made, in both cases causing fresh management issues (namely, resistance to changed processes or management of increased complexity). Unless the benefits of this approach far outweigh the risks and adversities they bring on, it is unwise to tread this path. As much as vendors know their wares, the customers know their needs. It is important in the COTS acquisition world that the customer spells out the needs in no uncertain terms. The right mix of stakeholders discussed in the earlier section would help to a great extent in supporting the requirements-gathering and the impact-analysis phases of the project.

We believe the approach we took has paid in the final analysis. And what is this analysis? It is the fact that we were able to use the characteristics represented by the various requirements to develop the criteria and the capability statements to assist in the evaluation process. We are glad that we achieved this clarity up front. We feel we have prevented the ill effects of making haste 
that may have occurred had the vendors been onsite and the meters been ticking. Given such constraints of cost and time, we could have exposed ourselves to a distorted focus during a critical phase of the effort. Because of our approach, we expect our project costs to be relatively stable. Equally important is the fact that having defined requirements and preferences would make it easier to seek what we need in the proposed solutions. Resulting from the approach was the Functional Specifications document, which served as an attachment to the Request for Proposal (RFP) and a reference point for evaluations.

Our approach has paid off by enabling us to

- establish the criteria that would be used to evaluate the proposals

- reason out the ability of the new system to fit the technical environment

- communicate to the prospective vendors that only certified and tested interfaces are needed to integrate the dependent systems

- communicate to the prospective vendors the data structures and the dependencies between systems

- discuss with the prospective vendors the business rules and the complexities at great length

- stick to one stance at all times with the prospective vendors

- communicate to the prospective vendors the business value that we anticipated from the implementation

\subsection{Definition of Expectations from the New System}

COTS acquisition techniques suggest the definition of expectations and the methods to identify capabilities of the proposed solutions to satisfy the requirements desired. To this end, the expectations and the means to assess the capabilities were drafted to assist in the evaluation process. They represented the characteristics and features desired of the proposed systems. They were grouped into appropriate categories namely, System Environment, Operating Environment, Functionality, Vendor Attributes, COTS Characteristics, and so on as partially illustrated in Table 2 in Section 5.4.

\subsection{Definition of Expectations About Vendor}

In an attempt to make sure we understood whom we were dealing with we had prepared a vendor survey. Parts of the survey sought information about the vendor including its Dunn and Bradstreet report, financial state of affairs, client list, and so on. We did this well in advance of product selection. This helped us avoid the risky position of having to make compromises to accommodate a faulty vendor selection. 


\subsection{Definition of the Grading Scale}

The COTS acquisition process advises the use of some reasonable method of quantifying the inferences drawn about a product's ability to satisfy expectations. While there exist automated packages for performing this task, we chose to define a scale (illustrated in Table 3 in Section 5.4) for the purpose. The scale was to measure the existence of functionality or lack of it, ability to modify or lack of it, ease of modification or lack of it, compatibility of the system with the current technical environment, perceivable cost impact, and so on. 


\section{The Search for a Solution}

The process discussed in this section is important and critical to the evaluation. It helps avoid dealings with novice vendors who are exploring avenues to enter the field. By skipping this process, one may end up spending substantial amounts of time and resources over a meaningless proposal—and probably be wedded to it as well.

\subsection{Representation at Key IT Conferences}

It was important to participate in the right conferences to get an understanding of the latest developments in the market. This provided an opportunity to network with vendors and with representatives of other organizations battling setbacks similar to those discussed in this paper. Such gatherings also provided the chance to draw the attention of the ERP vendors to the shortcomings of their products.

\subsection{Shortlisting Probable Vendors (COTS and Custom Solution Providers)}

Researching and creating a list of probable vendors was a difficult task. Since "birds of a feather flock together," conferences hosted by the ERP system vendor, Oracle Corporation, were targeted for our quest. There were vendors aplenty who were in some manner affiliated and/or committed to Oracle's business and technical strategy and dedicated to the financial software arena. We began talking with them, and soon we were known as a potential client with a problem needing a solution; before long we went into the serious business of talking in detail with a large number of vendors. Our defined requirements and related documents proved useful at these discussions; this form of preparedness reflected sufficient seriousness to attract mostly capable vendors. The degree of reciprocal seriousness helped in shortlisting the vendors.

\subsection{Request for Proposal (RFP)}

To establish the vendors' familiarity with the business context and their competency to undertake the task, a series of teleconferences, site visits, and demonstrations soon followed. An RFP was released to the vendors with intent to

- obtain the best possible bid 
- ensure an honest exchange in the marketplace and provide transparency to the vendors

- $\quad$ ensure compliance with the Department of Defense (DoD $)^{1}$ guidelines for IT acquisitions

\subsection{On-Site Pre-Bid Conference}

The vendors were invited to attend a mandatory day-long on-site meeting. The meeting was divided into two sessions. It was held to deal with the technical and the functional aspects of the project. This served as a platform to communicate and clarify the requirements. Business domain experts and technical experts from the SEI and CMU were on hand for this purpose. The meeting was followed by a post-conference question-and-answer exchange via email, which was circulated to all regardless of the initiator of the questions.

\subsection{Proposal Receipt and Opening}

After allowing substantial time for a response, we received proposals from 7 of the 11 vendors who attended the meeting. Three of them dropped out for reasons unknown. One vendor decided to refrain from participation since its product was not aligned to the business process discussed; the fact that we did not have to deal with the evaluation of an inappropriate product was a notable advantage resulting from our approach. To maintain the sanctity of the proposal-opening process, all stakeholders were invited to witness the event.

1 Being a Defense FFRDC, we are guided by contractual, Office of Management and Budget (OMB), Federal Acquisition Regulations, Defense Finance and Accounting Service, Defense Contract Audit Agency, and other relevant guidelines. 


\section{Knowledge of the Need}

The COTS process advises an absolute understanding of the needs, refined by appropriate giveand-take efforts between the various system owners and the user groups. On our project, this understanding was encapsulated in the functional specifications document discussed earlier. A questionnaire was used to elicit the users' thoughts on the essentials of a planning, forecasting, and budgeting solution that would help them manage their programs better. Brainstorming sessions with key players were held. The objectives of these sessions were also to establish critical changes related to the

- way business is being done

- way information is gathered, processed, and analyzed

- business drivers

- key performance indicators

Table 1: Sample Requirements

\begin{tabular}{|c|c|}
\hline Requirements & Description \\
\hline $\begin{array}{l}\text { Data extracts from } \\
\text { General } \\
\text { Ledger/Grants } \\
\text { Management System } \\
\text { and Human Resource } \\
\text { Information System } \\
\text { (HRIS) }\end{array}$ & $\begin{array}{l}\text { The system should extract data through appropriate } \\
\text { use of interfaces from the Oracle ERP and HRIS } \\
\text { systems }\end{array}$ \\
\hline Flexible Reporting & $\begin{array}{l}\text { Should be capable of providing highly flexible } \\
\text { reports run for different user-selected criteria and } \\
\text { presented in multiple formats as reflected in the } \\
\text { sample reports provided }\end{array}$ \\
\hline Burdening & $\begin{array}{l}\text { Should be capable of complex conditional } \\
\text { transformations and validation of burden structure } \\
\text { and negotiated rates for the appropriate funding } \\
\text { type, expenditure, task }\end{array}$ \\
\hline $\begin{array}{l}\text { Client Server } \\
\text { Architecture }\end{array}$ & Must be based on a client server architecture \\
\hline Forecasting & $\begin{array}{l}\text { Must be capable of extracting the actual } \\
\text { expenditures to support forecasting }\end{array}$ \\
\hline $\begin{array}{l}\text { Accounting } \\
\text { Structures }\end{array}$ & $\begin{array}{l}\text { Must be capable of supporting multiple accounting } \\
\text { structures }\end{array}$ \\
\hline
\end{tabular}


The consolidated comments drove the effort to freeze the scope. Table 1 above reflects the encapsulation of part of our understanding.. Caution with respect to "scope creep" and awareness of its dangers are strongly advised. No doubt requirements caused by changes to the environment with potential to derail the application, if not already factored in, would have to be prioritized for inclusion into the scope. For example, at the time of writing this paper, there came into being a plan to upgrade the ERP system (for the second time in a year). The selected vendor has already been cautioned about the upgrade and is expected to factor its impact into the implementation strategy. It is interesting to note that the vendor has substantial experience in the type of work related to the upgrade. It makes it that much easier to plan ahead. So the process of educating oneself and the vendor on matters affecting the enterprise-level infrastructure appears to be a continuous one, expected to bear fruit at the appropriate time. This approach has resulted in a common understanding of the project goals across the lifetime of the project. It has aided in the assessment of any need for process changes. It has also assisted in evaluating the need to tailor/modify the application or modify our infrastructure. Knowing the needs helped ascertain their satisfaction in the proposals received, thereby helping us to determine if we could buy the product versus building a system, which is essentially the buy versus build decision process. Evaluation of COTS solutions preceded the evaluation of custom solution proposals for obvious reasons - time to market, reduced risk, and so on.

With intent to understand our needs and their order of importance, we asked ourselves the questions listed below. They helped derive the knowledge that we needed to continue our efforts.

- What is the time to market?

- Do we need a solution tailored to fit the processes and external components exactly? If yes, do we have the resources to do it?

- Have we an idea of the post-implementation need to stay abreast with the developments and evolution in the external system's (Oracle ERP system in particular) product life cycle if we were to develop an in-house system?

- Have we an idea of what amount of commitment in terms of money and manpower is needed to stay abreast?

- Are the benefits that we expect to reap more than the costs of attempting the solution?

- If we do not adopt the idea of a customized solution, what are our options and how do we find them?

- What is our level of preparedness to deal with the bitter truth that there may truly be nothing available in the market and we need to go custom?

- If COTS products are offered as a solution, how do we know that the solution will satisfy our needs in their entirety? How do we evaluate the products within the scope of the functional and technical environment prevalent within the organization?

- Can the product be evaluated reasonably well with the help of a demonstration?

- Would the vendors' demonstration-usually known to represent a "right fit"- hold true at all points of the project life cycle and thereafter?

- Would a product evaluation be useful? 
- Do we need to be trained to undertake a product evaluation?

- Are we prepared to sink money into the training and discard if the product is not suitable?

- If offered several different solutions, are we prepared to evaluate all with appropriate training?

This is not an exhaustive list of the questions. There were several others that we considered. All the questions considered helped us understand the reality of the situation that we were faced with and the decisions we had to make. We needed additional experts to guide us in the process. And fortunately, we had the COTS program specialists to guide us. They required that we render some specific meaning to our effort by developing the scenarios and the expectations from the solutions that would satisfy the final goal. In the process, we managed to prepare several artifacts that helped us understand the scope of the project and the tasks that would have to be performed to achieve its goals. This formalization also satisfied the responsibility of the organization to exercise due diligence in matters of investment. The artifacts were to form the final basis of a common understanding of what we needed to do our jobs better. 


\section{Proposal Evaluation}

The effectiveness of the knowledge-gathering phase has a tremendous impact on the proposal evaluation. It provides the necessary guidance to look for the appropriate system attributes as reflected through the proposals. Prompting structured responses to the request for proposal made evaluation easier. This was accomplished through our structuring of the RFP, the functional specifications, and vendor survey. Awareness of the difficulty of the proposal evaluation process dawned very early in the project's life cycle. The evaluation team determined the quality of the solutions proposed and their ability to mitigate known problems.

In late December 2001 (note: the project was stalled for a period of seven months due to the ERP system upgrade), an RFP was released. The wait was warranted by the absence of key resources and the intent to implement in an upgraded environment.

\subsection{Proposal Evaluation Criteria}

The proposal evaluation criteria were made known to the vendors through the RFP; but not their order of importance, lest proposals be fabricated to win the contract. The statement by no means intends to inflict disrespect to the vendors. It instead serves as insulation against misrepresentation, while retaining the ability to attract good proposals. The criteria defined for evaluation included

1. overhead processing functionality

2. time periods handling

3. ability to process business in the pipeline

4. forecasting

5. revenue budgeting

6. effort translation to report full time equivalent

7. new-hire budgeting

8. system requirements

9. client server architecture

10. vendor attributes

11. COTS product characteristics

12. commercial terms 


\subsection{Functional Specifications Document}

The comprehensive Functional Specifications document referred to earlier spoke of, among other things, the situation, the problem, the environment and the goal.

\subsection{Vendor Survey}

A vendor survey, designed to evaluate the usefulness to the vendor of the RFP and related documents, helped us to gather feedback for assessing the need for improvement of future RFPs. The survey also served to provide information about the vendors themselves.

\subsection{Process Definition}

The project team sought the guidance of the COTS acquisition program specialists for insights into the method for defining the criteria. This led to brainstorming sessions that helped crystallize the evaluation criteria. Expectations were set for each of these criteria in order to assist in the evaluation of the systems. Capability statements were to be identified and/or inferred from the proposals. They were mapped to the criteria and followed by a score that numerically graded each capability. Tables 2 and 3 illustrate a sample of the criteria and the grading scale respectively.

Table 2: $\quad$ Illustration of the Evaluation Template-A Sample

\begin{tabular}{|l|l|l|l|l|}
\hline \multicolumn{2}{|c|}{ Proposed Budget System Proposal Evaluation Template } & $\begin{array}{l}\text { Vendor } \\
\text { Name: }\end{array}$ \\
\hline Requirement & \multicolumn{1}{|c|}{ Expectation } & Capability & Grade & Comments \\
\hline $\begin{array}{l}\text { Client/Server } \\
\text { Application }\end{array}$ & $\begin{array}{l}\text { Should be quick and scalable as } \\
\text { the user base grows. Average } \\
\text { response time should optimize } \\
\text { on speed, bandwidth, traffic, } \\
\text { process, etc. }\end{array}$ & & \\
\hline
\end{tabular}

2 As one Senior System Administrator pointed out, it is important to quantify the attributes sought of the system. In the illustration above, it would be meaningful, for example, to quantify "quick" with "subsecond response time" against the "performance" attribute. In our specific case, the application was meant to serve a small user base and we incorporated a section in the functional specifications document requiring that we be told what the expectations could be from the systems proposed. Our Senior Database Administrator endorsed the capability of the chosen system with respect to its satisfaction. It is advised that the need for satisfaction of specific system attributes be appropriately quantified on a case-by-case basis. 
Table 2: Illustration of the Evaluation Template-A Sample (Continued)

\begin{tabular}{|l|l|l|l|}
\hline Compatibility & $\begin{array}{l}\text { Should be compatible with the } \\
\text { current technical environment. } \\
\text { Windows NT/2000 or UNIX } \\
\text { Solaris } 2.6 \text { or higher, Oracle } \\
8.1 .6 \text { or higher, SQL Server } \\
2000, \text { Oracle AMG APIs. }\end{array}$
\end{tabular} \mid \begin{tabular}{l} 
\\
\hline
\end{tabular}

\section{Table 3: $\quad$ Illustration of the Grading Scale Used-A Sample}

\section{Grading Scale for the New Budget Solution Proposal Evaluation}

10 Fully addressed in current version

8 Partially addressed in current version; low-cost, no-impact/low-impact minor modifications will return fully desired functionality

7 Not addressed in current version; low-cost, no-impact/low-impact modifications will return fully desired functionality

6 Partially addressed in current version; high-cost, no-impact/low-impact modifications will return fully desired functionality

All evaluators were provided the guidelines for evaluation in unambiguous terms at the proposalopening meeting. Some of the interesting characteristics of this process - as seen from the evaluators' comments at the end of this paper- were the following:

- Evaluators felt respected by the level of participation afforded.

- Evaluators were allowed to evaluate not only criteria that mapped to their field of expertise but also other aspects of the proposal if they chose.

- Core technical staff members voiced happiness to be involved in the process.

- Common understanding of the capabilities of the solutions existed.

- Most evaluators turned in valuable evaluation comments.

- Grades appeared to be based on the evaluators' understanding of the proposal.

- Experts were used to review the proposals for better understanding.

- New questions were generated for the vendors' clarifications.

\subsection{Consolidation of Comments and Grades}

All comments and grades received from various individuals were consolidated for each COTS vendor that had submitted a proposal. When the results came, they were quite interesting: there 
was less than half a point separating three of the four serious contenders, the last having been discarded on grounds of not reflecting a comprehension of the needs.

\subsection{Reference Calls, Vendor Calls, and Research Group Analysis}

The COTS process did not lack advice for the situation. Inferences drawn from the COTS training prompted us to

- use references provided by the vendor

- use references known to internal members developed through proper networking and public relations with counterparts in the market place

- continue interaction with the vendor on various issues that crop up from time to time

Over a dozen references were called; these were spread across the country and included organizations large and small (universities, FFRDCs, and corporate bodies) that had implemented one or another of the products in question. We sought further validation through product research analyses, which pointed to significant problems regarding maintenance, implementation and modifiability concerns, as well as scarcity of skilled resources. This left just one fully capable COTS solution to choose.

\subsection{Recommendation}

If not for the COTS-based process undertaken, preparing the recommendation would have been a Herculean task - or so concurred our team members, based on their previous experiences. The recommendation with the supporting material was ready in quick time for management's consideration. The frequent updates to management and the strength of our process helped clear us for further negotiations with the vendor on terms - also within quick time.

\subsection{System Design - A Perception}

To assist in the resource allocation efforts with an aim of reducing the cost of implementation, we embarked on an effort to crystallize the issues, perceptions and interactions within the environment that the new system would be chartered into for a view that would foster reasoning. Several references $^{3}$ were used to construct the view. The effort resulted in an architectural rendering (Figure

3 The following definitions of software architecture were used to provide guidance in the effort:

- the structure of the components of a program/system, their interrelationships, and principles and guidelines governing their design and evolution over time [Garlan 95].

- the structure or structures of the system, which comprise software components, the externally visible properties of those components, and the relationships among them. By externally visible properties, we are referring to those assumptions other components can make of a component, such as its provided services, performance characteristics, fault handling, shared resource usage, and so on [Bass 98]. 
1) of the systems' context view. The components seen above and below it represent the ERP and HRIS systems that the new system would rely upon and offer guarantees to. The rendering helped to

1. map the SEI's and CMU's internal resources with the roles, responsibilities, and skills that were required for successful implementation of the solution

2. redefine the roles, responsibilities, and related skills that the vendor had to bring along to contribute to the success of the project

3. refine a proposal that was heavy on consulting costs, essentially trimming it by about a half of the costs originally proposed

4. clarify the assignment of tasks foreseen through an evaluation of the vendors' proposal

5. foster an understanding of the integration points that must be satisfied to make the implementation a success

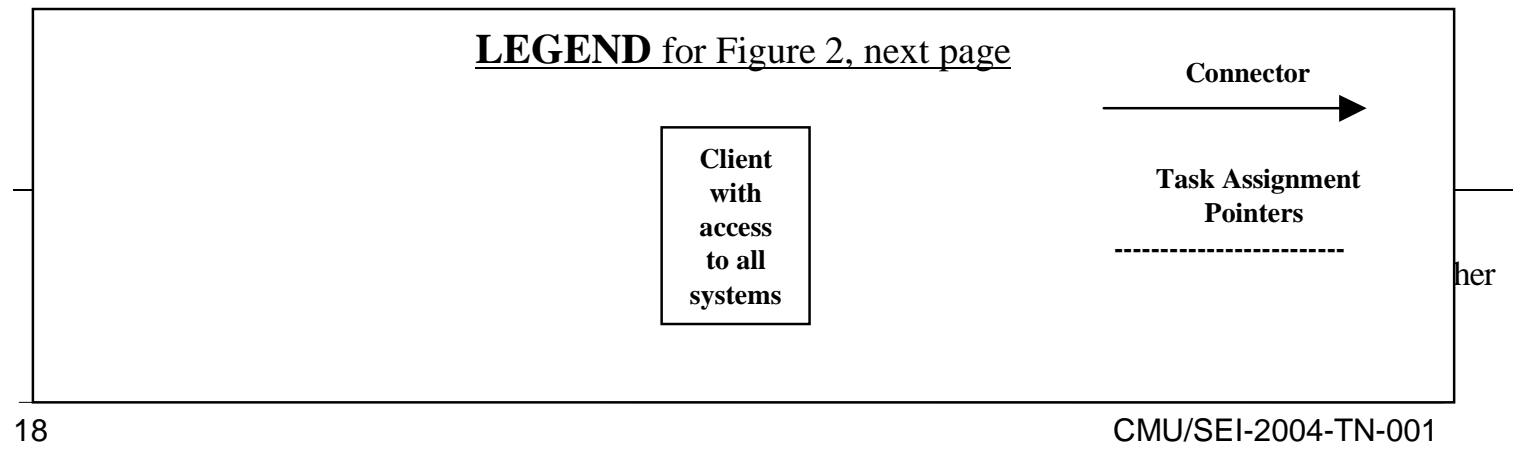




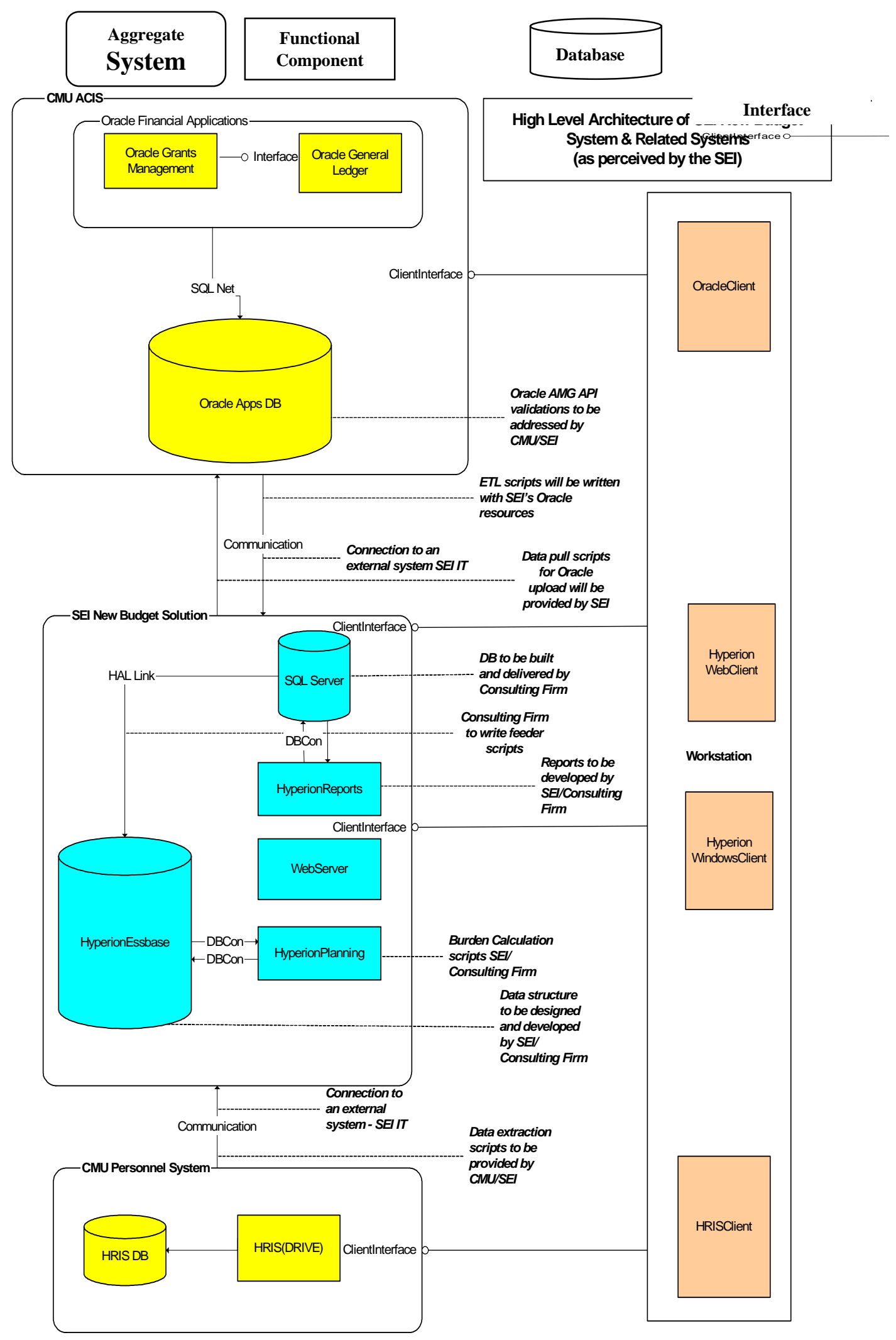

Figure 2: Context Diagram Representing the Integrated Environment 
Note: Different degrees of shading distinguish different full-fledged systems. All client software may not be installed for all users. 


\section{Value in Approach}

The Manager of Financial and Administrative Services anticipates an organizational culture change regarding future COTS acquisitions_-based on the positive experiences derived through the adoption of COTS techniques in this project execution. Let us capture the lessons learned through the use of this approach.

\subsection{Lesson 1 - Faith Is Fifty Percent of Healing}

If religiously practiced as they were by this team, the COTS acquisition techniques offer the promise of strong gains that can be directly experienced. These techniques are known for their robustness in helping to capture intricacies and weaknesses ahead of product selection. Simple examples include

- the ability to realize that one of the strong contenders relied on software services that were the subject of fresh alerts in terms of their vulnerability to security attacks

- knowledge of increased coding efforts to keep the system operational in an evolving IT environment with respect to another of the contenders

- the feeling of being in control most of the time

The demands of the process were so high that, at times, a tendency to compromise on the discipline crept in. But the hope of success in the final analysis urged us to persist on the chosen path. All round, confidence was high. Management and stakeholders reposed great faith in the team that had reposed great faith in the process. The project earned respect due to the approach. The vendors cooperated through the entire process.

\subsection{Lesson 2 - Knowledge Is Power}

The process fostered a deep understanding of the goals and the means to reach them. It helped field the right questions to the vendors and stakeholders at the right time (refer to Section 5). It promoted the reasoning of every single aspect that was relevant or critical to the success of the project. The difficult side was finding the right mix of stakeholders and managing their aspirations. The knowledge of the team responsible for the project should be equal to or greater than the sum of the knowledge of the stakeholders as the project progresses. This was the only way power balance could be maintained. 


\subsection{Lesson 3 - We Reap What We Sow}

It is important to support the evaluation process with the right mix of resources, a proper schedule, and a concerted effort. Some gains we experienced are represented in the answers to the following commonly asked questions.

Question: What does one stand to gain?

Answer: The following listed benefits are some that we experienced. They are derived from the efforts mentioned in the sections referred to in parentheses.

- $\quad$ ability to make well-informed decisions $(6.1,6.2,6.3,6.5)$

- ability to take calculated risks through appropriate tradeoffs $(3.3,6.5)$

- thorough comprehension of the known (3.3)

- $\quad$ preparedness to seek out and face the unknown $(3.4,3.5$, all of section 4)

- upfront knowledge of all the main and ancillary components and services needed as well as their costs to make the system fully operational (6.3)

- $\quad$ anticipated reduction in the day-after-the-fair surprises $(6.1,6.2,6.3,6.5)$

- $\quad$ wisdom of a well-analyzed investment $(4.3,6.4)$

We expect a shorter time to market since all the players, functional and technical, together are aware of all the building blocks needed to make this system operational in our environment. We only need to bring together the vendor's resources—-both consultants and software-and the internal resources - people and hardware — to get started with the implementation.

Question: Can the return be quantified?

Answer: While the return can be quantified in terms of the increased productivity and reduced risk anticipated, it remains to be seen what the facts are based on a post-implementation audit. However, we can conclude the following:

The risk of making a poor investment is reduced; there should exist a correlation between the amount of effort spent and the business value expected to be gained by following COTS product acquisition techniques (6.5).

Results are the effect of effort; the more the effort, the better the results; the depth of evaluation determines the strength of the foundation; having said this, we shall wait and watch what the results are considering that we have put in a fairly large effort. 


\section{Conclusion - Experience}

Adoption of the process and adherence to the techniques in their true spirit was a difficult grind. Validating all that was said and heard required amazing degrees of commitment. The fact that a greater part of the validation was done through external resources made it even harder. It should be mentioned, though, that almost all of our consulted resources were extremely kind in getting us the necessary input on the way to our decision and recommendation. The need for such validation was even higher since there is an internal process referenced by our DoD contract that keeps us functional, which requires a Request for Consent before any funding is committed. The COTS acquisition techniques did make this process a bit easier since we were ready with all the necessary documentation for the purpose.

As for the team, there was a very high degree of cooperation in getting tasks executed. There was a high degree of patience with the hope of getting something good out of the effort. It certainly was a tough call for team members to make time available from their busy schedules to accommodate the needs of the process that we adopted. It is also important to note that the managers of the project were committed to devoting the right amount of time for the work that needed to be done. We had a scheduled weekly meeting until the point in time that the evaluations had to begin. At every meeting there were action items clearly specified. Necessary tasks were accomplished and formed the basis of discussions in the ensuing meeting. These meeting were used to deliver, reason out, validate, and plan all the building blocks needed to begin the implementation.

The Chief Financial Officer was updated on the status of the project on a weekly basis during the one-on-one meetings with the project manager. Corrective action was prompt in being executed. Professional guidance was sought and applied where necessary with no delays. Every individual on the team and within the stakeholder groups played a key role in delivering the necessary input to bring the evaluation process to a successful close.

\subsection{Comments from the Team Members on Their Experience}

Let us hear what the Manager of Financial Analysis, a key member on the team, had to say:

"Before participating in the COTS evaluation process, I was very skeptical that a COTS product could solve our problems. But, by being involved in this process, I am satisfied that we have found our best solution."

A Business Analyst at the SEI had the following to say: 
"The COTS process enabled the Budget Team to discriminate between the requirements that were absolutely necessary and those requirements that we could live without. This was in my opinion the most challenging part of the entire process. Had it not been for the training and guidance provided by the COTS folks, the determination of the necessary attributes and those that are not necessary would not have been completed with the same degree of accuracy."

The COTS Program Specialists rendered the following opinion:

"The team was totally inexperienced in this kind of selection, naïve about some aspects-in other words, completely typical of a team facing such a challenge for the first time. Their success is, in our opinion, due to their ability to understand and their willingness to embrace the principles we introduced into the discussions."

A Senior System Administrator had the following to say:

"...some of the evaluation parameters were not quantified. Specifically, it indicates that (paraphrased) performance should be quick and optimized for bandwidth.... Which begs the question, 'how fast is quick?' Numbers are extremely important...” And he went on to add, when asked about the pre-proposal conference, "It was a good exercise."

\subsection{Expectations}

The process appears to support a shorter final leg of the project. Confidence in this assertion stems from the fact that all players involved in its implementation are well educated and informed about the project goals, the process goals, the roles, the responsibilities, and the accountability. Though the final outcome is months away, it seems that the project is poised for a smooth journey ahead. Look out for the facts in future papers in the Preacher's Practice series. The series is committed to reinforcing the software engineering discipline with facts from the home turf, the Software Engineering Institute, Pittsburgh, PA 15213, U.S.A. 


\section{Acronyms}

$\begin{array}{ll}\text { ACIS } & \text { Administrative Computing Information Services } \\ \text { BDI } & \text { Budget Development Integrator } \\ \text { CBS } & \text { COTS-based systems } \\ \text { CFO } & \text { Chief Financial Officer } \\ \text { CMU } & \text { Carnegie Mellon University } \\ \text { COTS } & \text { commercial Off-the-shelf } \\ \text { ERP } & \text { Enterprise Resource Planning } \\ \text { FABS } & \text { Financial and Business Services } \\ \text { FFRDC } & \text { federally funded research and development center } \\ \text { RE } & \text { Grants Management (An Oracle ERP Module) } \\ \text { RFC } & \text { request for consent } \\ \text { GL } & \text { General Ledger (An Oracle ERP Module) } \\ \text { HRIS } & \text { Human Resource Information System } \\ & \end{array}$




\section{References}

All URLs are accurate as of the publication date of this document.

[Bass 98] Bass, L; Clements, P; \& Kazman, R. Software Architecture in Practice. Reading, MA: Addison-Wesley Longman, 1998.

[Garlan 95] Garlan, D \& Perry, D. "Introduction to the Special Issue on Software Architecture." IEEE Transactions on Software Engineering 21,4 (April 1995).

[IEEE 00] IEEE Computer Society, Software Engineering Standards Committee. IEEE Recommended Practice for Architectural Description of Software Intensive Systems (IEEE Std 1471-2001) New York, NY: IEEE, Inc., 2000. <http://www.idi.ntnu.no/ letizia/swarchi/IEEE1471.pdf> (2000). 


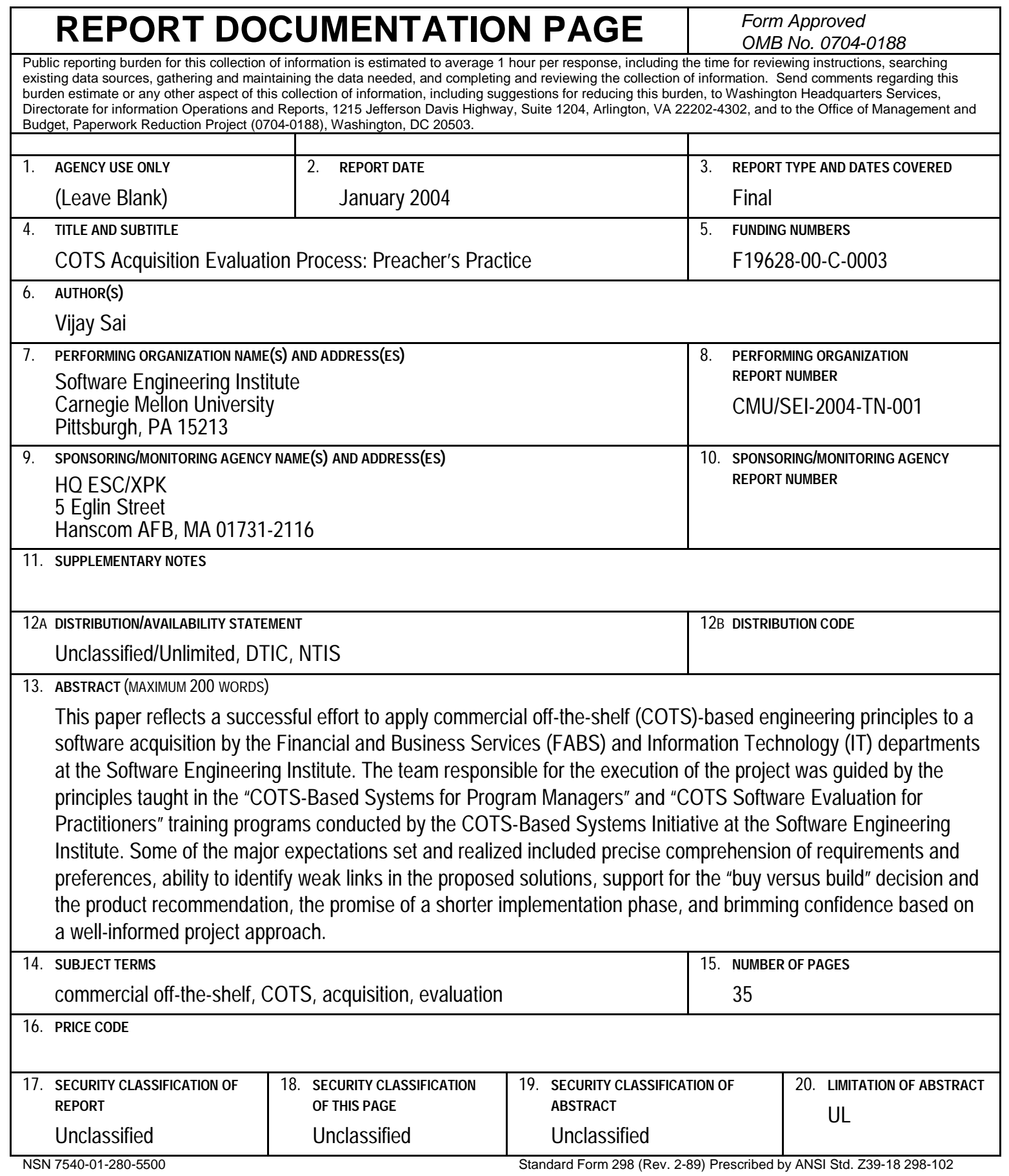

